Int. J. Electrochem. Sci., 16 (2021) Article ID: 210742

\title{
The Microstructure and Properties of Nitrided Chromium Coating on 316 Stainless Steels Fabricated by Electrodeposition and Electrolytic Nitriding for PEMFC Bipolar Plate
}

\author{
Yaxue Wang ${ }^{1}$, Chengwei Deng ${ }^{2}$, Yi Sun ${ }^{2}$, Xixun Shen ${ }^{1, *}$, and Yanyan Zhu ${ }^{1}$ \\ ${ }^{1}$ Shanghai Key Laboratory of Materials Protection and Advanced Materials in Electric Power, \\ Shanghai Engineering Research Center of Heat-exchange System and Energy Saving, College of \\ Environmental and Chemical Engineering, Shanghai University of Electric Power, Shanghai 200090, \\ China \\ ${ }^{2}$ Space Power Technology State Key Laboratory, Shanghai Institute of Space Power-Sources,Shanghai \\ 200245, China \\ *E-mail: shenxixun@ shiep.edu.cn
}

doi: $10.20964 / 2021.07 .71$

Received: 29 March 2021 / Accepted: 18 May 2021 / Published: 31 May 2021

In this paper, a nitrited chromium composite coating is fabricated as a protective coating for the 316 stainless steels bipolar plates by a combination process of electrodeposition and liquid-phase plasma electrolysis. The pre-treatment of chemical micro etching on the stainless steel substrate is also done to improve the adhesion between the coating and the substrate before electroplating and give the coating a rough surface with micro-nano structure. The electrochemical analysis revealed that the composite coating remarkably improve the corrosion resistance of the 316 stainless steels bipolar plates. The corrosion current density of the nitrited chromium composite coating in the simulated cathodic environment of PEMFC is only less than $9.35 \times 10^{-7} \mathrm{~A} / \mathrm{cm}^{2}$, which nearly is three orders of magnitude lower than that of stainless steels substrate. Moreover, the composite coating has good long-term stability in corrosion resistance.After a long time of immersion, the corrosion current density of the coating remains at the same level as that before immersion. The interface contact resistance value of nitrited chromium composite coating is $4.9 \mathrm{~m} \Omega \cdot \mathrm{cm}^{2}$ under the pressure of $1.4 \mathrm{MPa}$, which meets the conductivity requirements of the bipolar plate.

Keywords: Stainless steel bipolar plate; Etching; Nitriding; Corrosion resistance; Interface contact resistance 
(C) 2021 The Authors. Published by ESG (www.electrochemsci.org). This article is an open access article distributed under the terms and conditions of the Creative Commons Attribution license (http://creativecommons.org/licenses/by/4.0/). 